\title{
Ovarian Stromal-Leydig Cell Tumor
}

National Cancer Institute

\section{Source}

National Cancer Institute. Ovarian Stromal-Leydig Cell Tumor. NCI Thesaurus. Code C39977.

A rare, benign and well circumscribed stromal tumor of the ovary. It is characterized by the presence of a fibrotic stroma with clusters of Leydig cells. The Leydig cells contain crystals of Reinke. Patients may present with virilization. 